\title{
Adherence to Antibiotic Prophylaxis in Children with Vesicoureteral Reflux
}

\author{
Esequiel Rodriguez Jr., Dana A. Weiss, and Hillary L. Copp \\ UCSF Department of Urology, University of California, 400 Parnassus Ave, A633 San Francisco, CA 94143-0738, USA
}

Correspondence should be addressed to Esequiel Rodriguez Jr., rodrigueze2@urology.ucsf.edu

Received 16 November 2010; Accepted 26 January 2011

Academic Editor: Ranjiv Mathews

Copyright (C) 2011 Esequiel Rodriguez Jr et al. This is an open access article distributed under the Creative Commons Attribution License, which permits unrestricted use, distribution, and reproduction in any medium, provided the original work is properly cited.

\begin{abstract}
Vesicoureteral reflux (VUR) affects approximately $1 \%$ of children and may predispose a child with a bladder infection to develop pyelonephritis and renal scarring. To prevent these potential sequelae, one accepted treatment option for VUR includes lowdose continuous antibiotic prophylaxis (CAP) to maintain urine sterility until the condition resolves. Despite the widespread use of CAP, little data exists regarding adherence to long-term antibiotic therapy. Not only will poor adherence to CAP potentially preclude the intended benefit, but also nonadherence with antibiotic regimens may carry untoward effects including unnecessary treatment changes for presumed antibiotic failure, emergence of resistant organisms, and compromised clinical trial outcomes. We present an overview of medication adherence in children with VUR, discuss possible consequences of nonadherence to antibiotic prophylaxis, and suggest ways to improve adherence. We raise awareness of issues related to nonadherence relevant to healthcare providers, investigators, and the community.
\end{abstract}

\section{Introduction}

Vesicoureteral reflux (VUR), a common congenital abnormality, affects approximately $1 \%$ of infants and children. It may predispose a child with a bladder infection to the development of pyelonephritis, which may lead to renal scarring and hypertension [1]. To prevent these potential longterm sequelae, one accepted treatment option for persistent VUR includes low-dose continuous antibiotic prophylaxis (CAP). Since reflux has a $5-13 \%$ annual spontaneous resolution rate, CAP may be offered as a protective measure to maintain urine sterility until the condition resolves $[2,3]$. Herein, the physician assumes the patient is taking the antibiotic as prescribed on a daily basis.

Despite the widespread use of CAP, there is a paucity of data regarding patient adherence to long-term antibiotic therapy. The intended benefit of any medication will be completely achieved only if patients adhere to the prescribed treatment regimen. Not only will nonadherence to CAP potentially preclude the intended benefit, but also nonadherence with antibiotic regimens may carry potential untoward effects. For example, nonadhernence to antibiotics is associated with the emergence of resistant organisms $[4,5]$. In addition, recurrent UTIs in nonadherent patients with VUR may be interpreted as treatment failure, and may instigate unnecessary treatment changes. Nonadherence may also compromise clinical trial outcomes and, consequently, treatment guidelines derived from them.

The aim of this paper is to provide a brief overview of medication adherence in children with VUR, discuss possible consequences of nonadherence to antibiotic prophylaxis, and suggest ways to improve adherence. Our goal is to raise awareness of issues related to nonadherence relevant to healthcare providers, investigators, and the community.

\section{Adherence}

The intended benefit of any prescribed medication will be fully achieved only if the patient adheres to the prescribed treatment closely. Adherence to a medication regimen is generally defined as the degree to which the medications taken reflect the prescribing healthcare provider's intention $[6,7]$. 
While there is no consensus on what constitutes adequate adherence, an adherence rate of $80 \%$ or greater (antibiotic coverage for $80 \%$ of the year or more) is commonly used in the literature [8]. Similarly, there is no consensual gold standard method for measuring whether patients take the medication prescribed or not. Current methods used to measure compliance are best categorized as direct and indirect methods [8-10]. Direct methods include biologic blood markers, level of medicine or metabolite in blood or urine, and direct observation of ingestion. Indirect methods include patient/caregiver questionnaire, medication diary, medical record, pill counts, rates of prescription refills, and patient's clinical response. In general, direct methods more reliably predict adherence; however, they are more costly and time consuming. Many of the indirect methods are more practical; however, they have been shown to overestimate adherence [8-10]. Using a parent questionnaire, Smyth showed that $97 \%$ of parents reported giving prophylactic antibiotics every day; however, only $67 \%$ of urine samples tested positive for antibacterial substance [11]. In a similar study of children with VUR, in the group without recurrent urine infections $84 \%$ of parents reported that their children were taking antibiotics at 6 months but only $28 \%$ had a positive urine antibiotic activity test; at 1 year $57 \%$ reported their children were taking antibiotics but only $17 \%$ had a positive urine test [12]. It's important to note that even direct measuring methods with ultrasensitive blood or urine tests may not be entirely reflective of adherence. Many patients improve medication compliance just before seeing their healthcare provider [13]. In this scenario, blood or urine medication level only indicates that the medication was recently taken, but does not ascertain adherence in between visits.

Regardless of the method used to measure adherence, a common denominator among children with chronic diseases such as asthma, diabetes, HIV, and skin diseases, is that poor adherence is a ubiquitous phenomenon. In a quantitative review of children with chronic diseases, DiMatteo estimated that only about $70 \%$ of patients were adherent to treatment recommendations [14]. However, other studies have noted even lower rates, averaging about 50-60\%, with decreasing compliance rates noted over time [15-18]. In a prospective study of children with asthma, adherence rates to inhaled corticosteroids decreased from $73 \%$ at 4 months to $59 \%$ at 12 months [19]. Even in clinical trials where patients often receive more attention and, by nature, may self-select for inherently motivated subjects, poor adherence rates are not uncommon. In the PENTA 5 randomized controlled trial evaluating HIV treatment in children, $25 \%$ of subjects were nonadherent with antiretroviral regimens [20].

Congruent with the poor adherence rates witnessed in children with other chronic diseases, adherence with prophylactic antibiotics in children with VUR is poor. Additionally, with time, adherence with long-term antibiotic decreases dramatically $[10,12]$. Using large pharmacy claims databases in children with VUR, two recent studies showed poor prophylactic antibiotic adherence as defined by an adherence rate of less than $80 \%$. In the first study, Hensle and colleagues reported a $17 \%$ adherence rate [21]. Similarly, in the second study, Copp et al. reported a 40\% adherence rate [22]. These two recent reports substantiate previous findings where antibiotic adherence rates at one year among children with VUR were only $57 \%$ by parental report and $17 \%$ by measured urine levels of antibiotic activity [12].

\section{Potential Consequences of Nonadherence}

Omitting antibiotic doses may result in breakthrough UTIs, which in addition to the discomfort and inconvenience caused, may increase the risk for pyelonephritis and renal scarring [1]. Furthermore, recurrent UTI's in nonadherent patients with VUR may be interpreted as treatment failure, and may instigate unnecessary medication changes or additional interventions such as imaging studies and/or surgical correction of the underlying condition. Unnecessary tests and treatments, hospital admissions, and additional healthcare provider visits increase healthcare costs $[23,24]$. Moreover, indirect costs and effects such as workdays missed by parents and school absences by children create a burden that is difficult to quantify.

In addition to affecting the individual patient, poor adherence may also have local and global ramifications. Bacterial drug resistance is a growing problem and has become a major public health concern. For example, E Coli, which causes $70-90 \%$ of first febrile uncomplicated UTIs in children [25-28], is resistant to sulfonamides in up to $27 \%$ of cases in certain regions of the United States [29]. The emergence of drug resistant strains is more likely to occur in nonadherent patients, as subtherapeutic antibiotic levels have been shown to foster the development of resistant organisms $[4,5,30]$.

Lastly, poor adherence may compromise clinical trial outcomes and, consequently, treatment recommendations derived from them. Four well-referenced contemporary randomized controlled studies in children with VUR question the benefit of antibiotic prophylaxis as UTI, pyelonephritis, and renal scaring were not statistically different among patients receiving versus not receiving CAP [30-33]. All four studies failed to account for adherence to the antibiotic treatment therapy. Since nonadherence has also been shown to be an important factor in the research setting [20], a possible explanation for these findings could simply be due to a lack of adherence to the daily antibiotic prophylaxis regimen.

As investigators we cannot assume that children/parents are adherent to treatment. We must adequately account for and report adherence rates in our studies. Adherence estimates determined solely by the attending doctor should be discouraged as they have been shown to be inaccurate and overestimate true rates $[34,35]$. In a prospective study measuring compliance with antibiotic prophylaxis in children with sickle cell anemia, adherence rate was low when measured by urine tests (56\%) and parental interview (48\%), but overestimated by analysis of medical records (89\%) [34]. Given its complexity, to maximize accuracy, a combination of methods for measuring adherence is advocated. In this manner we can more confidently begin to interpret our study results. 


\section{Improving Adherence}

Given the potential individual and global ramifications of noncompliance, interventions to promote compliance are needed. This is particularly important in the pediatric population where adherence to treatment regimens can be further influenced by involvement of family members, developmental capacity of the patient, and by unique psychosocial issues implicit at a given age [36-40]. Hence, a multifaceted approach tailored to the individual child/parent is needed to improve adherence [41-43]. Support from ancillary health care providers such as nurses, behavioral specialists, and pharmacists may increase adherence and should be used as needed when feasible [44-46]. We discuss approaches to enhance adherence for three age groups: infant/toddler/preschool $(0-<5 \mathrm{yrs})$, young child (5$<11 \mathrm{yrs}$ ), and adolescent (11-<19yrs).

In infants/toddlers/preschoolers, the caregiver is primarily responsible for the administration of the antibiotic. Enhancing patient/parent-doctor communication has a pivotal role in improving medication compliance [37, 47]. Here, the health care provider should assure that the caregiver has a solid understanding of the disease process, the benefits of the treatment regimen, and the risks of noncompliance. Dosing and timing of the medication prescribed should be discussed. As forgetfulness can be the main reason cited by caregivers for omitting antibiotic doses [48], short interval follow-up visits should be scheduled. This gives the healthcare provider an excellent opportunity to assess adherence in a nonjudgmental way, and reiterate the importance of following the treatment outlined. Also, the medication dose can be adjusted, as infants grow rapidly during this age.

Although there is a paucity of literature describing the most effective ways of improving adherence in young children, in general a combination of behavioral and educational strategies are most beneficial [49]. Education is typically targeted at the caregiver responsible for administering the medication, and involves written or verbal information about the child's illness, delineating reasons for treatment, and discussing potential consequences of poor adherence [49]. Other forms of education include informational videotapes, structured educational home visits by nurses or counselors, and group discussions [49-56]. When feasible, similar age appropriate verbal, written, and visual educational materials should be provided to the child. There is a wide spectrum of behavioral interventions for children which are simple and practical including positive reinforcement with rewards, diaries, stickers on calendars, goal setting, contracts, and linking medication intake with established daily routines, among others $[49,57-63]$. The most common behavioral intervention is the token reinforcement system, where adherence to medication is rewarded by tokens or another form of reward [64-66]. It is important to inquire about medication/formulation preferences before prescribing prophylactic antibiotics (pill, capsule, or elixir form, and preferred flavor). Changing a medication to a more palatable form was shown to be effective in increasing adherence rates in children [67, 68]. A common complaint by parents/children with liquid nitrofurantoin is its poor taste. Perhaps the poor palatability may partly explain the distinctly low adherence rate of only $2 \%$ observed in children on nitrofurantoin prophylaxis for VUR [22]. Finally, the involvement of family members and schools can be valuable in improving adherence in children $[35,47]$.

While the underlying reasons for nonadherence in adolescents are complex and not fully understood, issues involving self-esteem, body image, coping mechanisms, and self motivation are contributing factors [38]. As children age and enter adolescence they become more autonomous and assume a greater responsibility for their own treatment [69]. In general, increased age is associated with lower adherence across many chronic pediatric illnesses including asthma, anxiety disorders, diabetes, and HIV [69-72]. Similar findings were noted by the Hensle et al. [21] and Copp et al. [22] groups with pediatric patients on CAP for VUR. This underscores the need for educational strategies targeted at the adolescent, as well as continuous parental oversight particularly as the child/adolescent is granted more autonomy.

\section{Conclusion}

The goal of prophylactic antibiotics is to maintain urine sterility and prevent ascending urinary tract infections in children with vesicoureteral reflux until the condition resolves spontaneously or is surgically corrected. Nonadherence to prophylactic antibiotics among children is highly prevalent and may be associated with medication failure, unnecessary changes in treatment protocols, increased healthcare costs, and increased antibiotic resistance patterns. We must strive to identify risk factors for nonadherence, and implement behavioral/educational algorithms to improve adherence. Finally, in light of emerging data supporting the contention that prophylactic antibiotics may not be protective against UTIs, controlled studies that monitor and adequately account for adherence rates are needed. Until such studies are available, we cannot reliably determine whether antibiotic prophylaxis is effective in preventing urinary tract infection in children with vesicoureteral reflux.

\section{References}

[1] S. H. Jacobson, S. Hansson, and B. Jakobsson, "Vesico-ureteric reflux: occurrence and long-term risks," Acta Paediatrica, vol. 88, no. 431, pp. 22-30, 1999.

[2] S. P. Greenfield, M. Ng, and J. Wan, "Resolution rates of low grade vesicoureteral reflux stratified by patient age at presentation," Journal of Urology, vol. 157, no. 4, pp. 14101413, 1997.

[3] C. W. Schwab, H. Y. Wu, H. Selman Grahame, H. H. Smith, H. M. Snyder, and D. A. Canning, "Spontaneous resolution of vesicoureteral reflux: a 15-year perspective," Journal of Urology, vol. 168, no. 6, pp. 2594-2599, 2002.

[4] F. C. Tenover and J. E. McGowan, "Reasons for the emergence of antibiotic resistance," American Journal of the Medical Sciences, vol. 311, no. 1, pp. 9-16, 1996.

[5] I. Bollgren, "Antibacterial prophylaxis in children with urinary tract infection," Acta Paediatrica, vol. 88, no. 431, pp. 48-52, 1999. 
[6] T. E. Nevins, "Non-compliance and its management in teenagers," Pediatric Transplantation, vol. 6, no. 6, pp. 475479, 2002.

[7] E. Lehane and G. McCarthy, "Medication non-adherenceexploring the conceptual mire," International Journal of Nursing Practice, vol. 15, no. 1, pp. 25-31, 2009.

[8] S. E. Andrade, K. H. Kahler, F. Frech, and K. A. Chan, "Methods for evaluation of medication adherence and persistence using automated databases," Pharmacoepidemiology and Drug Safety, vol. 15, no. 8, pp. 565-574, 2006.

[9] E. Vermeire, H. Hearnshaw, P. van Royen, and J. Denekens, "Patient adherence to treatment: three decades of research. A comprehensive review," Journal of Clinical Pharmacy and Therapeutics, vol. 26, no. 5, pp. 331-342, 2001.

[10] J. F. Steiner and A. V. Prochazka, "The assessment of refill compliance using pharmacy records: methods, validity, and applications," Journal of Clinical Epidemiology, vol. 50, no. 1, pp. 105-116, 1997.

[11] A. R. Smyth and B. A. Judd, "Compliance with antibiotic prophylaxis in urinary tract infection," Archives of Disease in Childhood, vol. 68, no. 2, pp. 235-236, 1993.

[12] K. S. Panaretto, J. C. Craig, J. F. Knight, R. Howman-Giles, P. Sureshkumar, and L. P. Roy, "Risk factors for recurrent urinary tract infection in preschool children," Journal of Paediatrics and Child Health, vol. 35, no. 5, pp. 454-459, 1999.

[13] S. R. Feldman, F. T. Camacho, J. Krejci-Manwaring, C. L. Carroll, and R. Balkrishnan, "Adherence to topical therapy increases around the time of office visits," Journal of the American Academy of Dermatology, vol. 57, no. 1, pp. 81-83, 2007.

[14] M. R. DiMatteo, "Variations in patients' adherence to medical recommendations: a quantitative review of 50 years of research," Medical Care, vol. 42, no. 3, pp. 200-209, 2004.

[15] P. V. Burkhart and J. Dunbar-Jacob, "Adherence research in the pediatric andadolescent populations: a decade in review," in Chronic Illness in Children: An Evidence-Based Approach, L. Hayman, M. M. Mahon, and J. R. Turner, Eds., Springer, New York, NY, USA, 2002.

[16] S. Jay, I. F. Litt, and R. H. Durant, "Compliance with therapeutic regimens," Journal of Adolescent Health Care, vol. 5, no. 2, pp. 124-136, 1984.

[17] M. A. Rapoff, "Compliance with treatment regimens for pediatric rheumatic diseases," Arthritis Care and Research, vol. 2, no. 3, pp. S40-S47, 1989.

[18] R. S. Festa, M. H. Tamaroff, F. Chasalow, and P. Lanzkowsky, "Therapeutic adherence to oral medication regimens by adolescents with cancer. I. Laboratory assessment," Journal of Pediatrics, vol. 120, no. 5, pp. 807-811, 1992.

[19] L. Lasmar, P. Camargos, J. Bousquet, E. Goulart, E. Sakurai, and M. Carvalhais, "Factors related to lower adherence rates to inhaled corticosteroids in children and adolescents: a prospective randomized cohort study," Journal of Tropical Pediatrics, vol. 55, no. 1, pp. 20-25, 2009.

[20] D. M. Gibb, R. L. Goodall, V. Giacomet, L. McGee, A. Compagnucci, and H. Lyall, "Adherence to prescribed antiretroviral therapy in human immunodeficiency virus-infected children in the PENTA 5 trial," Pediatric Infectious Disease Journal, vol. 22, no. 1, pp. 56-62, 2003.

[21] T. W. Hensle, G. Hyun, A. L. Grogg, and M. Eaddy, "Part 2: examining pediatric vesicoureteral reflux: a real-world evaluation of treatment patterns and outcomes," Current Medical Research and Opinion, vol. 23, no. 4, pp. S7-S13, 2007.

[22] H. L. Copp, C. P. Nelson, L. D. Shortliffe, J. Lai, C. S. Saigal, and W. A. Kennedy, "Compliance with antibiotic prophylaxis in children with vesicoureteral reflux: results from a national pharmacy claims database," Journal of Urology, vol. 183, no. 5, pp. 1994-2000, 2010.

[23] T. L. Wandstrat and B. Kaplan, "Pharmacoeconomic impact of factors affecting compliance with antibiotic regimens in the treatment of acute otitis media," Pediatric Infectious Disease Journal, vol. 16, no. 2, pp. S27-S29, 1997.

[24] J. A. Rizzo and W. R. Simons, "Variations in compliance among hypertensive patients by drug class: implications for health care costs," Clinical Therapeutics, vol. 19, no. 6, pp. 1446-1457, 1997.

[25] J. M. P. Silva, J. S. Santos Diniz, V. S. P. Marino et al., "Clinical course of 735 children and adolescents with primary vesicoureteral reflux," Pediatric Nephrology, vol. 21, no. 7, pp. 981-988, 2006.

[26] D. Prais, R. Straussberg, Y. Avitzur, M. Nussinovitch, L. Harel, and J. Amir, "Bacterial susceptibility to oral antibiotics in community acquired urinary tract infection," Archives of Disease in Childhood, vol. 88, no. 3, pp. 215-218, 2003.

[27] S. Ladhani and W. Gransden, "Increasing antibiotic resistance among urinary tract isolates," Archives of Disease in Childhood, vol. 88, no. 5, pp. 444-445, 2003.

[28] S. Ashkenazi, S. Even-Tov, Z. Samra, and G. Dinari, "Uropathogens of various childhood populations and their antibiotic susceptibility," Pediatric Infectious Disease Journal, vol. 10, no. 10, pp. 742-746, 1991.

[29] M. E. Jones, J. A. Karlowsky, D. C. Draghi, C. Thornsberry, D. F. Sahm, and J. S. Bradley, "Rates of antimicrobial resistance among common bacterial pathogens causing respiratory, blood, urine, and skin and soft tissue infections in pediatric patients," European Journal of Clinical Microbiology and Infectious Diseases, vol. 23, no. 6, pp. 445-455, 2004.

[30] E. H. Garin, F. Olavarria, V. G. Nieto, B. Valenciano, A. Campos, and L. Young, "Clinical significance of primary vesicoureteral reflux and urinary antibiotic prophylaxis after acute pyelonephritis: a multicenter, randomized, controlled study," Pediatrics, vol. 117, no. 3, pp. 626-632, 2006.

[31] M. Pennesi, L. Travan, L. Peratoner et al., "Is antibiotic prophylaxis in children with vesicoureteral reflux effective in preventing pyelonephritis and renal scars? A randomized, controlled trial," Pediatrics, vol. 121, no. 6, pp. e1489-e1494, 2008.

[32] G. Roussey-Kesler, V. Gadjos, N. Idres et al., "Antibiotic prophylaxis for the prevention of recurrent urinary tract infection in children with low grade vesicoureteral reflux: results from a prospective randomized study," The Journal of Urology, vol. 179, no. 2, pp. 674-679, 2008.

[33] G. Montini, L. Rigon, P. Zucchetta et al., "Prophylaxis after first febrile urinary tract infection in children? A multicenter, randomized, controlled, noninferiority trial," Pediatrics, vol. 122, no. 5, pp. 1064-1071, 2008.

[34] E. L. Bitarães, B. M. de Oliveira, and M. B. Viana, "Compliance with antibiotic prophylaxis in children with sickle cell anemia: a prospective study," Jornal de Pediatria, vol. 84, no. 4, pp. 316$322,2008$.

[35] C. K. Tebbi, "Treatment compliance in childhood and adolescence," Cancer, vol. 71, no. 10, pp. 3441-3449, 1993.

[36] B. A. Smith and M. Shuchman, "Problem of nonadherence in chronically ill adolescents: strategies for assessment and intervention," Current Opinion in Pediatrics, vol. 17, no. 5, pp. 613-618, 2005.

[37] M. R. DiMatteo, "The role of effective communication with children and their families in fostering adherence to pediatric 
regimens," Patient Education and Counseling, vol. 55, no. 3, pp. 339-344, 2004.

[38] C. K. Tebbi, K. M. Cummings, M. A. Zevon, L. Smith, M. Richards, and J. Mallon, "Compliance of pediatric and adolescent cancer patients," Cancer, vol. 58, no. 5, pp. 1179 $1184,1986$.

[39] I. M. Friedman and I. F. Litt, “Adolescents' compliance with therapeutic regimens. Psychological and social aspects and intervention," Journal of Adolescent Health Care, vol. 8, no. 1, pp. 52-67, 1987.

[40] I. M. Friedman, I. F. Litt, and D. R. King, "Compliance with anticonvulsant therapy by epileptic youth: relationships to psychosocial aspects of adolescent development," Journal of Adolescent Health Care, vol. 7, no. 1, pp. 12-17, 1986.

[41] D. Matsui, "Current issues in pediatric medication adherence," Pediatric Drugs, vol. 9, no. 5, pp. 283-288, 2007.

[42] J. A. Cramer, "Optimizing long-term patient compliance," Neurology, vol. 45, no. 2, pp. S25-28, 1995.

[43] M. Crespo-Fierro, "Compliance/adherence and care management in HIV disease," Journal of the Association of Nurses in AIDS Care, vol. 8, no. 4, pp. 43-54, 1997.

[44] R. B. Haynes, H. McDonald, A. X. Garg, and P. Montague, "Interventions for helping patients to follow prescriptions for medications," Cochrane Database of Systematic Reviews, no. 2, Article ID CD000011, 2002.

[45] M. L. Bouvy, E. R. Heerdink, J. Urquhart, D. E. Grobbee, A. W. Hoe, and H. G. M. Leufkens, "Effect of a pharmacist-led intervention on diuretic compliance in heart failure patients: a randomized controlled study," Journal of Cardiac Failure, vol. 9, no. 5, pp. 404-411, 2003.

[46] L. Osterberg and T. Blaschke, "Adherence to medication," The New England Journal of Medicine, vol. 353, no. 5, pp. 487-497, 2005.

[47] F. M. Ross, "Patient compliance-whose responsibility?" Social Science and Medicine, vol. 32, no. 1, pp. 89-94, 1991.

[48] B. M. de Oliveira, M. B. Viana, C. L. Zani, and A. J. Romanha, "Clinical and laboratory evaluation of compliance in acute lymphoblastic leukaemia," Archives of Disease in Childhood, vol. 89, no. 8, pp. 785-788, 2004.

[49] A. J. Dean, J. Walters, and A. Hall, "A systematic review of interventions to enhance medication adherence in children and adolescents with chronic illness," Archives of Disease in Childhood, vol. 95, no. 9, pp. 717-723, 2010.

[50] D. Baum and T. L. Creer, "Medication compliance in children with asthma," Journal of Asthma, vol. 23, no. 2, pp. 49-59, 1986.

[51] V. M. Berrien, J. C. Salazar, E. Reynolds, and K. McKay, "Adherence to antiretroviral therapy in HIV-infected pediatric patients improves with home-based intensive nursing intervention," AIDS Patient Care and STDs, vol. 18, no. 6, pp. 355363, 2004.

[52] H. J. Farber and L. Oliveria, "Trial of an asthma education program in an inner-city pediatric emergency department," Pediatric Asthma, Allergy and Immunology, vol. 17, no. 2, pp. 107-115, 2004.

[53] L. Holzheimer, H. Mohay, and I. B. Masters, "Educating young children about asthma: comparing the effectiveness of a developmentally appropriate asthma education video tape and," Child: Care, Health and Development, vol. 24, no. 1, pp. 85-99, 1998.

[54] D. M. Hughes, M. McLeod, B. Garner, and R. B. Goldbloom, "Controlled trial of a home and ambulatory program for asthmatic children,” Pediatrics, vol. 87, no. 1, pp. 54-61, 1991.
[55] M. S. Jay, R. H. DuRant, T. Shoffitt et al., "Effect of peer counselors on adolescent compliance in use of oral contraceptives," Pediatrics, vol. 73, no. 2, pp. 126-131, 1984.

[56] L. Salleras Sanmarti, J. Alcaide Megias, M. N. Altet Gomez et al., "Evaluation of the efficacy of health education on the compliance with antituberculosis chemoprophylaxis in school children. A randomized clinical trial," Tubercle and Lung Disease, vol. 74, no. 1, pp. 28-31, 1993.

[57] M. Berkovitch, D. Papadouris, D. Shaw, N. Onuaha, C. Dias, and N. F. Olivieri, "Trying to improve compliance with prophylactic penicillin therapy in children with sickle cell disease," British Journal of Clinical Pharmacology, vol. 45, no. 6, pp. 605-607, 1998.

[58] S. Bonner, B. Zimmerman, D. Evans, M. Irigoyen, D. Resnick, and R. Mellins, "An individualized intervention to improve asthma management among urban Latino and AfricanAmerican families," Journal of Asthma, vol. 39, no. 2, pp. 167$179,2002$.

[59] R. S. Fennell, L. M. Foulkes, and S. R. Boggs, "Familybased program to promote medication compliance in renal transplant children," Transplantation Proceedings, vol. 26, no. 1, pp. 102-103, 1994.

[60] M. F. Hovell, C. L. Sipan, E. J. Blumberg et al., "Increasing Latino adolescents' adherence to treatment for latent tuberculosis infection: a controlled trial," American Journal of Public Health, vol. 93, no. 11, pp. 1871-1877, 2003.

[61] M. A. Rapoff, J. Belmont, C. Lindsley, N. Olson, J. Morris, and J. Padur, "Prevention of nonadherence to nonsteroidal antiinflammatory medications for newly diagnosed patients with juvenile rheumatoid arthritis," Health Psychology, vol. 21, no. 6, pp. 620-623, 2002.

[62] J. T. Shope, "Intervention to improve compliance with pediatric anticonvulsant therapy," Patient Counselling and Health Education, vol. 2, no. 3, pp. 135-141, 1980.

[63] N. A. Smith, J. P. Seale, and P. Ley, "Effects of intervention on medication compliance in children with asthma," Medical Journal of Australia, vol. 144, no. 3, pp. 119-122, 1986.

[64] M. A. Rapoff, C. B. Lindsley, and E. R. Christophersen, "Improving compliance with medical regimens: case study with juvenile rheumatoid arthritis," Archives of Physical Medicine and Rehabilitation, vol. 65, no. 5, pp. 267-269, 1984.

[65] E. Greenan-Fowler, C. Powell, and J. W. Varni, "Behavioral treatment of adherence to therapeutic exercise by children with hemophilia," Archives of Physical Medicine and Rehabilitation, vol. 68, no. 12, pp. 846-849, 1987.

[66] P. R. Magrab and Z. L. Papadopoulou, "The effect of a token economy on dietary compliance for children on hemodialysis," Journal of Applied Behavior Analysis, vol. 10, no. 4, pp. 573578, 1977.

[67] C. M. Tucker, R. S. Fennell, T. Pedersen, B. P. Higley, C. E. Wallack, and S. Peterson, "Associations with medication adherence among ethnically different pediatric patients with renal transplants," Pediatric Nephrology, vol. 17, no. 4, pp. 251$256,2002$.

[68] M. Blaiss, "Current concepts and therapeutic strategies forallergic rhinitis in school-age children," Clinical Therapeutics, vol. 26, no. 11, pp. 1876-1889, 2004.

[69] E. L. McQuaid, S. J. Kopel, R. B. Klein, and G. K. Fritz, "Medication adherence in pediatric asthma: reasoning, responsibility, and behavior," Journal of Pediatric Psychology, vol. 28, no. 5, pp. 323-333, 2003.

[70] C. L. Hanson, S. W. Henggeler, and G. A. Burghen, "Social competence and parental support as mediators of the link 
between stress and metabolic control in adolescents with insulin-dependent diabetes mellitus," Journal of Consulting and Clinical Psychology, vol. 55, no. 4, pp. 529-533, 1987.

[71] J. T. Walkup, M. J. Labellarte, M. A. Riddle et al., "Searching for moderators and mediators of pharmacological treatment effects in children and adolescents with anxiety disorders," Journal of the American Academy of Child and Adolescent Psychiatry, vol. 42, no. 1, pp. 13-21, 2003.

[72] P. L. Williams, D. Storm, G. Montepiedra et al., "Predictors of adherence to antiretroviral medications in children and adolescents with HIV infection," Pediatrics, vol. 118, no. 6, pp. e1745-e1757, 2006. 


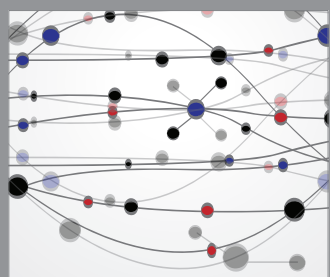

The Scientific World Journal
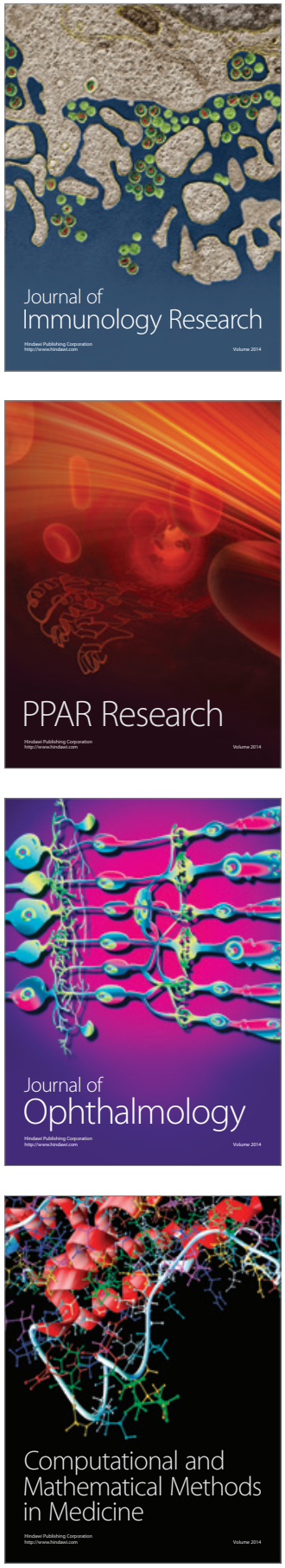

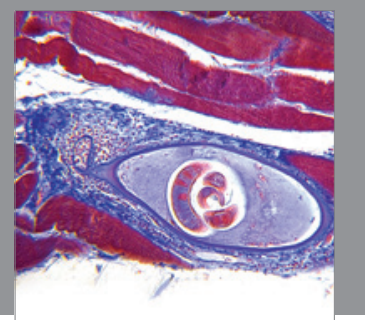

Gastroenterology

Research and Practice
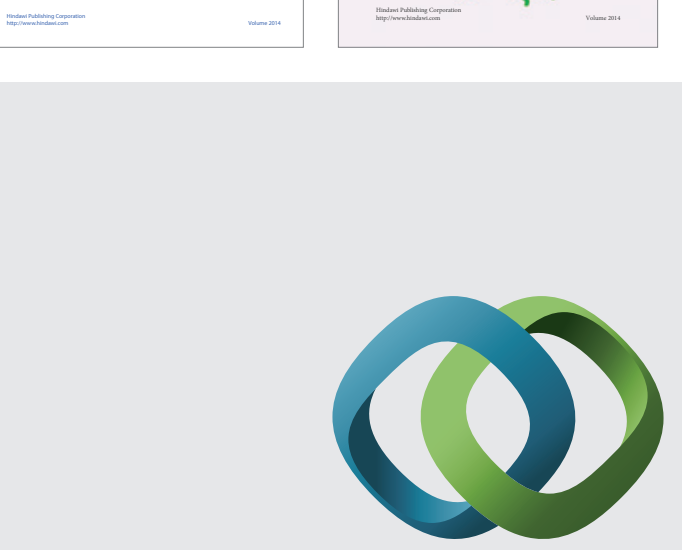

\section{Hindawi}

Submit your manuscripts at

http://www.hindawi.com
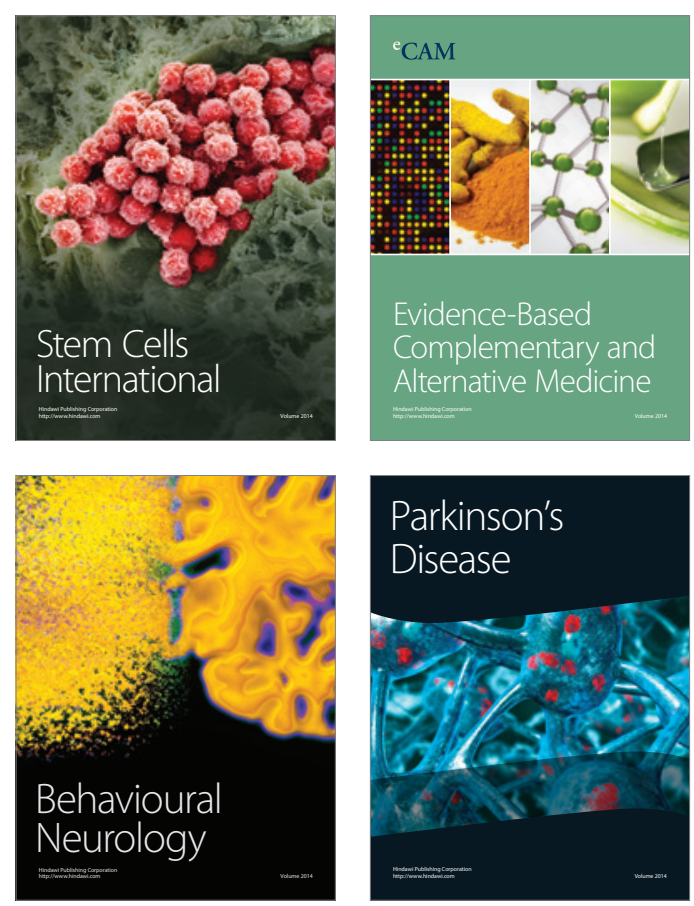

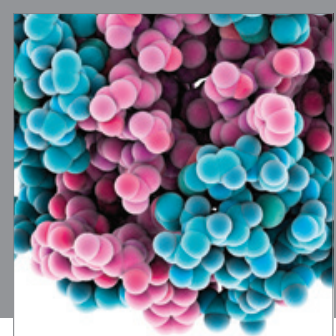

Journal of
Diabetes Research

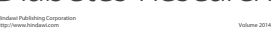

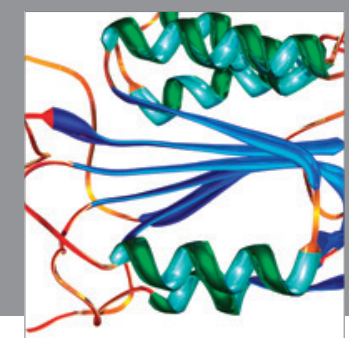

Disease Markers
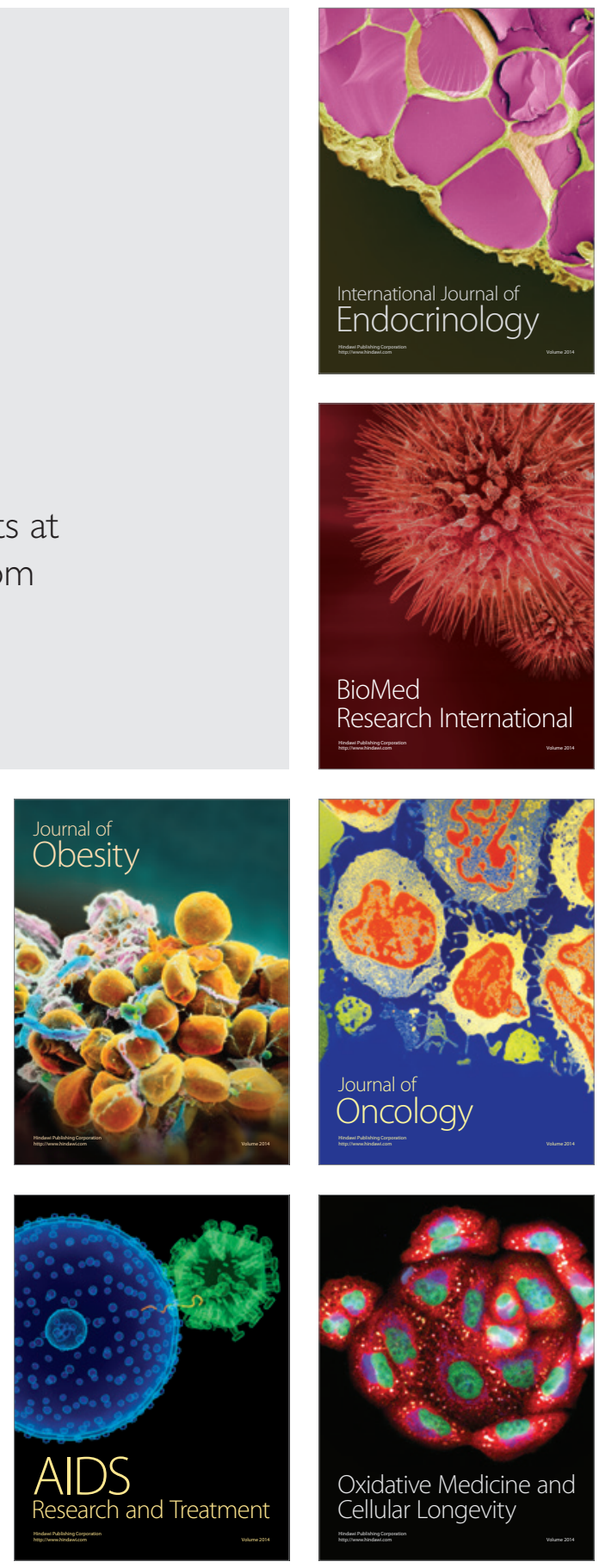